Mabasan, Vol. 8, No. 1, januari-Juni 2014: 1-13

\title{
POTRET PERJUANGAN TOKOH UTAMA DAN NILAI DIDIK DALAM NOVEL GURU DANE KARYA SALAMAN FARIS SERTA RELEVANSINYA DALAM PEMBELAJARAN SASTRA DI MADRASAH ALIYAH
}

\section{(THE STRUGGLE OF THE MAIN CHARACTER AND EDUCATIONAL VALUES IN NVEL GURU DANE BY SALMAN FARIS AS WELL AS THE RELEVANCE IN TEACHING LITERATURE AT SENIOR HIGH SCHOOL)}

\author{
Badrin, Hilmiati \\ BTN Mekar Griya Asri, Blok E No. 24 Perampuan \\ Labuapi, Lombok Barat, NTB, Indonesia \\ Post-el: muhammadbadrin@yahoo.co.id. \\ hilmiatibadrin@yahoo.co.id
}

Diterima: 25 Agustus 2014; Direvisi: 13 Oktober 2014; Disetujui: 24 Oktober 2014

\begin{abstract}
The problem in this study was a struggle of the main character in Novel Guru Dane (NGD) by Salman Faris. The objectives of this study are to describe: (1) the structure of the NGD by Salman Faris, (2) the educational values, (3) and the relevance of the educational values with the teaching material of literature subject at Senior High School. This research was a descriptive qualitative research. The data collected through documentation and interview. The data analysis applied the theory of structural, theory of semiothics, and theory of learning with the steps of identification, classification, description, interpretation, and explanation. The conclusions of this research are (1) NGD consist of some mutual completing elements, namely theme, characterizations, setting, message, and plot. (2) the effort of the main character to arouse the degnity of the people of Sasak by supporting plurality, humanity, and identity was divided into (a) building cognitive awareness about humanity, (b) building social awareness, (c) breaking down arrogance and the greatness of mistycal things, (d) implanting class awareness, and (e) implanting knighthood/noble actions to the people of sasak; (3) The educational values in the NGD are (a) willingness to sacrifice and to be responsible, (b) respect to the rights and obligations of each other, (c) stickiness to principles and defensiveness to trial, (d) religiousness, (e) patience and lovingness, $(f)$ honesty, $(g)$ hardwork, $(h)$ cooperation, $(i)$ didiscipline; (4) The values in the NGD are in line with those in the standard of content, the standard of competence, and the basic competence of literature teaching. It also give understanding on the values applications as guidences of behaving, and fit the reality in society which make it relevant to be an object of literature teaching and learning.
\end{abstract}

Keywords: struggle, the novel Guru Dane, educational values, literature teaching, MA

\begin{abstract}
Abstrak
Permasalahan dalam makalah ini adalah perjuangan tokoh utama dalam Novel Guru Dane (selanjutnya disingkat NGD) karya Salman Faris. Tujuan makalah ini mendeskripsikan (1) struktur NGD, (2) nilai-nilai didik, dan (3) relevansi nilai-nilai didik tersebut dalam pembelajaran sastra di Madrasah Aliyah (MA). Makalah ini merupakan penelitian kualitatif dengan sifat deskriptif analitik. Pengumpulan data menggunakan metode kepustakaan dan metode wawancara. Analisis data menerapkan teori structural, semiotika, dengan mengikuti langkah-langkah identifikasi, klasifikasi, deskripsi, interpretasi, dan eksplanasi. Simpulan makalah ini adalah (1) NGD terdiri atas beberapa unsur yang saling melengkapi, yakni tema, penokohan, latar, amanat, dan alur; (2) bentuk perjuangan tokoh utama untuk membangkitkan harga diri orang Sasak dengan menjunjung tinggi nilai peluralitas, humanitas, dan kekuatan identitas yang dikelompokan menjadi, (a) membangun kesadaran kognitif tentang kemanusiaan, (b) membangun kesdaran sosial (c) meruntuhkan keangkuhan atau kisaran yang bergantung pada benda-benda mistik, (d) menanamkna kesadaran kelas, dan (e) menanakan sifat
\end{abstract}


Mabasan, Vol. 8, No. 1, januari-Juni 2014: 1-13

kesatria sebagai orang sasak; (3) nilai didik dalam NGD, yaitu (a) rela berkorban dan bertanggung jawab, (b) saling menghargai hak dan kewajiban, (c) teguh pendirian dan tahan uji, (d) religious, (e) sabar dan penyanyang, (f) jujur, (g) kerja keras, (h) kerjasama, dan (i) disiplin; (4) nilai-nilai yang terdapat dalam NGD sesuai dengan standar isi, standar kompetensi, kompetensi dasar, pembelajaran sastra, memberikan pemahaman, dan pengaplikasian nilai-nilai tersebut sebagai pedoman untuk bertingkah laku, serta sesuai dengan realitas dalam masyarakat sehingga relevan dijadikan sebagai bahan pembelajaran sastra.

Kata kunci: perjuangan, Novel Guru Dane, nilai didik, pembelajaran sastra, MA

\section{Pendahuluan}

Karya sastra merupakan media pembelajaran yang efektif bagi pengarang untuk menyampaikan pesan dan menanamkan nilai pendidikan dalam benak pembaca. Apabila karya sastra tersebut berbentuk novel, informasi kemasyarakatan tersebut ada kalanya terasa sangat nyata dan hidup karena jalinan hubungan tokohtokohnya. Dalam novel, terdapat banyak pengalaman bernilai pendidikan yang positif, apalagi jika novel yang disajikan dipilih dengan pertimbangan yang mendalam.

Karya sastra yang baik mampu meninggalkan pesan yang mendalam bagi pembacanya. Pembaca dengan bebas melarutkan diri bersama dengan karya itu dan mendapat kepuasan darinya. Selain itu, pembaca juga diharapkan mendapatkan nilai-nilai luhur yang terkandung di dalamnya. Nilai luhur yang terkandung dalam karya sastra salah satunya nilai moral dalam cerita biasanya dimaksudkan sebagai suatu sarana yang berhubungan dengan ajaran moral tertentu yang bersifat praktis, yang dapat diambil dan ditafsirkan lewat cerita yang bersangkutan oleh pembaca. Moral menyangkut sesuatu yang baik dan buruk pada perubahan manusia sebagai manusia dalam kehidupan masyarakat. Oleh karena itu, masalah moral melekap dalam kehidupan masyarakat.

Novel sebagai salah satu bentuk karya sastra diharpakan dapat munculkan pemikiran-pemikiran yang positif, bahan perenungan, pengalaman, pendidikan, dan pesan moral sehingga pembaca peka terhadap masalah-masalah sosial dan mendorong untuk berperilaku yang baik. Salah satu novel yang diduga mempresentasikan persoalan sosial dan juga merepresentasikan norma estentik sesuai dengan masa kelahirannya adalah novel Guru Dane (selanjutnya disingkat NGD) karya Salman Faris. Novel ini diterbitkan November tahun 2011 oleh Percetakan Sekolah Tinggi Keguruan Ilmu Pendidikan (STKIP) Press Lombok. NGD dipilih untuk dikaji karena memiliki beberapa kelebihan yang dilihat dari segi isi, bahasa dan 
merupakan novel lokal yang dinilai banyak memiliki nilai didik beserta pesan-pesan kemanusiaan yang setara dengan novelnovel nasional Novel diharapkan dapat dijadikan sebagai materi pembelajaran bahasa dan sastra Indonesia di Madrasah Aliyah.

Tulisan ilmiah ini akan menjawab tiga permasalahan yakni bagaimana sruktur NGD, nilai-nilai didik, dan relevansi nialinilai didik tersebut dalam pembelajaran sastra di Madrasah Aliyah (MA). Sesuai

\section{Kerangka teori}

Sepengetahuan penulis, kajian terhadap NGD belum ada. Hal ini dapat terjadi karena NGD merupak novel lokal dan relatif baru. Namun, penggunaan pendekatan strukturalisme-semiotik sudah banyak dilakukan baik di tesis maupun artikel, di antaranya Handayani (2005) yang membahas aspek moral dalam novel Biru karya Fira Basuki yang menggunakan pendekatan semiotik; Purwaningsih (2006) yang membahas mengenai perbandingan nilai edukatif dan karakter tokoh wanita dalam novel La Barka karya Nh. Dini dengan Larung karya Ayu Utami berupa tinjauan intertekstualitas; Maroh (2006) yang mengkaji nilai-nilai edukatif dalam novel Al Fadhillah karya Musthafa Lutfi Al Manfaluth; Imron dengan permasalahan yang telah disebutkan diatas, maka tujuan penelitian ini yaitu mendeskripsikan struktur NGD, nilai-nilai didik, dan relevansi nilai-nilai didik tersebut dalam pembelajaran sastra di MA. Hasil penelitian ini diharapkan dapat bermanfaat untuk memperkaya wawasan, sebagai sumber acuan, dan dapat dijadikan model penelitian strukturalisme-semiotik terhadap kajian karya sastra yang lain.

(2007) yang melakukan pengkajian nilai pendidikan multikultura dalam novel BurungBurung Rantau; Rita Sahara (2012) yang membahas mengenai nilai-nilai edukatif dalam novel Derap-Derap Tasbih karya Hadi S. Khuli berupa tinjauan sosiologi.

Perbedaan penelitian ini dengan penelitian terdahulu terletak pada objek kajiannya yaitu $N G D$ dan relevansinya dlam pembelajaran sastra. Novel ini merupakan karya penulis dari Lombok yang memaparkan tokoh-tokoh dan perilaku masyarakat Lombok sehingga diharapkan potensi novel lokal ini dapat dimanfaatkan sebagai materi ajar dalam pembelajaran sastra dan layak untuk dikaji.

Penelitian ini menggunakan teori strukturalisme-semiotik. Menurut Hawkes, karya sastra merupakan sebuah struktur yang unsure-unsurnya atau bagian-bagiannya saling 
berjalinan erat. Dalam struktur itu, unsurunsur tidak mempunyai makna dengan sendirinya. Maknanya ditentukan oleh saling hubungannya dengan unsur-unsur lainnya dan keseluruhan atau totalitasnya (dalam Jabrohim, 2003:93, Ratna, 2004:91—94, Nurgiyantoro, 2010:56). Fokus penelitian ini adalah perjuangan tokoh utama sehingga analisis struktur diarahkan pada analisis tema, alur, perwatakan, latar, dan sudut pandang.

Analisis nilai-nilai didik pada penelitian ini memanfaatkan teori semiotik. Semiotik (semiotics) didenfinisikan oleh Ferdinand de Saussure sebagai ilmu atau metode analisis untuk mengkaji tanda. Sementara menurut Preminger (dalam Jabrohim, 2003:68) semiotik adalah ilmu tentang tanda-tanda. Semiotik mempelajari sistem-sistem, aturanaturan, konvensi-konvensi yang memungkinkan tanda-tanda tersebut mempunyai arti. Pendapat ini sejalan dengan Nurgiyantoror (2010:40) yang menyatakan makan, yang ditentukan oleh konvensinya, karya sastra merupakan tanda-tanda yang bermakna. Menurut Pierce ada tiga jenis tanda berdasarkan hubungan antara tanda dengan yang ditandakan, yaitu (1) ikon, yaitu tanda yang secara inheren memiliki kesamaan dengan arti yang ditunjuk; (2) indeks yaitu tanda yang mengambil hubungan kausal dengan apa yang ditandakan; (3) simbol yaitu tanda yang memiliki hubungan makna dengan yang ditandakan bersifat arbitrer, sesuai dengan konvensi suatu lingkungan sosial tertentu.

Kajian ini akan direlevasikan dengan pembelajaran sastra. Oleh karena itu, pada bagian ini, akan dikemukakan teori belajar yang relevan yakni teori belajar kontekstual, humanistik, dan konstuktivistik. Pendekatan kontekstual mengarahkan pembelajaran kea rah yang lebih bermakna bagi siswa. Proses pembelajaran bersifat alami karena siswa bekerja dan mengalami, bukan sekadar mentransfer pengetahuan dari guru ke siswa. Strategi pembelajaran lebih dipentingkan daripada hasil (Yamin, 2008:150-153, Trianto, 2011:104, Johnson, 2011:35). Lima bentuk belajar dalam meode kontekstual adalah bentuk belajar mengaitkan (relating), mengalami (experiencing), menerapkan (applying), kerjasama (cooperating), dan mentransfer (transferring). Dalam tulisan ilmiah ini, pembelajaran sastra yang bermakna bagi siswa akan dilihat dari sisi nilai-nilai positif dalam $N G D$ kemudian dikaitkan dengan realita yang dialami siswa dalam kehidupan sehari-hari. Pembelajaran sastra seperti ini dapat menggunakan model pembelajaran VCT (Value Clarification Technique). Taniredja, dkk. (2011:87-89) mengatakan bahwa VCT merupakan teknik 
pengajaran untuk membantu siswa dalam mencari dan menentukan suatu nilai yang dianggap baik dalam menghadapi suatu persoalan melalui proses menganalisis nilai yang sudah ada dan tertanam dalam diri siswa.

Budiningsih (2005:8) mengemukakan bahwa menurut teori humanistik belajar harus dimulai dan ditunjukkan untuk kepentingan memanusiakan manusia. Teori belajar humanistik akan membantu para pendidik dalam memahami arah belajar pada dimensi yang lebih luas, sehingga upaya pembelajaran apapun dan pada konteks manapun akan selalu diarahkan untuk mencapai tujuan tersebut. Teori belajar yang relevan dengan teori ini adalah teori konstruktivistik.

Pandangan konstruktivistik adalah pengetahuan tidak diterima secara pasif, pengetahuan tidak boleh ditransfer begitu saja, melainkan diinterpretasikan, dibangun secara aktif oleh individu. Slavin (1994:225) menyatakan bahwa "One of the most important principles of educational psychology is that teachers cannot simply give students knowledge. Students must construct knowledge in their own minds". Maksud dari pendapat tersebut adalah dalam psikologi pendidikan salah satu prinsip yang sangat penting adalah guru tidak dapat dengan mudah memberikan pengetahuan pada siswa, tetapi siswa harus menkonstruksi sendiri pengetahuan dalam pikiran mereka.

Berdasarkan uraian di atas, upaya membina dan membimbing siswa khususnya melalui apresiasi teks $N G D$ memiliki tujuan untuk menjadikan manusia yang berbudi, memperoleh nilai-nilai, dan mengamalkan nilai-nilai tersebut dalam kehidupan seharihari dengan mengklarifikasi nilai-nilai yang baik dan buruk yang sebaiknya digunakan oleh siswa. Pengetahuan dan nilai-niali tersebut harus dikontruksikan sesuai dengan pengetahuan dan sikap siswa. Pengetahuan dan nilai-nilai yang telah dimiliki digunakan untuk membangun pengetahuan dan nilai yang baru sehungga pembelajaran lebih bermakna bagi siswa.

\section{Metode penelitian}

Tulisan ilmiah ini merupakan penelitian kualitatif dengan sifat deskriptif analisis. Data terdiri atas dua jenis, yaitu data primer dan data sekunder. Data primer bersumber dari $N G D$, sedangkan data sekunder dari responden yaituguru dan siswa MA.

Pengumpulan data dilakukan dengan menggunakan metode kepustakaan dan wawancara. Metode kepustakaan digunakan untuk menyimpulkan data dari $N G D$. Metode ini menerapkan teknik catat dengan langkahlangkah identifikasi data, coding data, dan 
memasukan data pada tabel data. Metode wawancara digunakan untuk mengumpulkan data yang berkaitan dengan relevansi nilainilai yang ditentukan dalam $N G D$ khususnya yang berkaitan dengan bentuk perjuangan tokoh dengan pembelajaran sastra. Instrumen wawancara adalah daftar pertanyaan. Analisis data menggunakan teori strukturalisme, teori semiotik, yang digunakan untuk menganalisis bentuk perjuangan tokoh. Hasil analisis, khususnya yang berkaitan dengan nilai-nilai positif, kemudian dilihat relevansinya dengan pembelajaran sastra di MA.

\section{Pembahasan}

\subsection{Struktur NGD}

Dalam NGD, ditemukan beberapa tokoh penting di antaranya Guru Dane, Sumar, Ketut Kolang, Putu Sunari, Haji Majid, Jero Mihram dan banyak lagi tokoh lainnya. Penulis memfokuskan kajian pada bentuk perjuangan tokoh Guru Dane dan Sumar yang terangkai dalam alur cerita. Untuk memepermudah analisis alur, $N G D$ peneliti bagi menjadi empat bagian yang masing-masing menunjukkan perbedaan waktu. Setiap bagian terdiri atas beberapa peristiwa. Bagian pertama ketika guru dane melakukan semedi untuk mengisi dirinya selama empat puluh hari empat puluh malam. Pada waktu itu ia masih didampingi oleh anak angkatnya

bernama Sumar. Bagian kedua, setelah melakukan semedi selama empat puluh hari empat puluh malam Guru Dane memiliki kemampuan dalam mengobati dan memecahkan masalah masyarakat baik orang Sasak maupun orang Bali dan pada bagian ini juga Sumar sudah mulai curiga atas gerakangerakan dan ide Guru Dane. Bagian ketiga adalah kehidupan Guru Dane yang mampu mengambil simpati dan menyatukan semangat masyarakat Sasak dan Bali yang kejam, serta perseteruan yang terjadi antara Guru Dane dan Sumar. Bagian keempat, Guru Dane ditangkap kemudian diasingkan dan perjalanan perjuangan Sumar dengan tarekat sepi-nya memperjuangkan kebebasan orang Sasak.

Berdasarkan pengamatan terhadap bagian-bagian cerita, diketahui bahwa ada dua alur yang terdapat dalam $N G D$ yaitu alur longgar dan alur lurus. Pada alur longgar ada kemungkinan untuk mencopot salah satu peristiwa tanpa merusak keutuhan cerita. Dalam hal ini, penulis mencopot beberapa bagian dari cerita yang tidak terkait dengan area atau bagian yang dianalisis penulis, yakni pertemuan Sumar dengan Marni sahabat dari masa kecilnya di pasar; pertemuan Sumar dengan orang gila di hutan;pertemuan si Cebol dengan Guru Dane; pernikahan Guru Dane dengan Sinar. 
Alur kedua yang terdapat dalam $N G D$ adalah alur lurus yakni peristiwa-peristiwa dilukiskan berurutan dari awal hingga akhir. Pada tahap awal (A) tokoh-tokoh dalam novel diperkenalkan. Cerita bergerak maju dengan menceritakan tokoh Guru Dane dan anak angkatnya Sumar yang dengan setia bersamanya melakukan semedi selama empat puluh hari empat puluh malam sehingga memiliki kemampuan mengobati dan memberikan jalan keluar atas segala masalah yang dihadapi masyarakat Sasak dan Bali. Ia kemudian mampu menyita simpati dan menyatukan semangat masyarakat Sasak dan Bali akar umput untuk melawan, memberontak pada perwangsa Sasak yang lain, bangsawan Bali yang kejam serta kolonial Belanda yang sedang berkuasa. Melalui mitos Datu Selaparang, ia menyebarkan kesadaran persamaan hak di atas segala perbedaan kasta dan kelas sosial yang sengaja dilestraikan penguasa kala itu. Kondisi ini pun menyulut pada konflik kemudian cerita berlanjut ketahap tikaian (B) yakni berbagai permasalahan yang mewarnai hari-hari Guru Dane dan Sumar. Pengakuan pertokohan Guru Dane oleh masyarakat bawah menimbulkan kecemburuan di golongan atas, bangsawan-bangsawan Sasak. Pengaruh yang selama ini memanyungi mereka terasa terkurangi oleh pertokohan
Guru Dane yang secara bersamaan menanamkan kesadaran tentang adanya kesamaan derajat antar sesama. Mereka pun menganggap Guru Dane sebagai ancaman. Bumerang inilah yang menjadikan Guru Dane harus menghadapi dua sisi. Di satu sisi, ia harus menghadapi penjajahan Belanda dan di sisi lain, dia harus menghadapi ketersanjungan bangsaawan Sasak. Akibat dari apa yang ada pada tahap tikaian, maka cerita pun berkembang pada tahap gawatan (C). Pada tahap gawatan ini diceritakan perilaku pada bangsawan Sasak yang pada masa penguasaan Bali lebih memilih menghianati dan memeras masyarakatnya sendiri. Hal itu dilakukan dengan cara berpihak pada penguasa Bali hanya karena diiming-imingi harta dan kekuasaan yang secara tidak sadar sebenarnya merupakan setitik dari hak mereka sendiri. Perasaan jengkel Guru Dane semakin menjadi ketika para bangsawan tersebut mengulangi masalahnya denga menyembah dam meminta bantuan kepada Belanda untuk mengusir Bali. Keinginan itu muncul karena gelimang kenikmatan sudah tidak diberikan lagi oleh Bali, bukan karena kesadaran keterjajahan suku bangsanya. Guru Dane menyadari bahwa tidak menutup kemungkinan hal tersebut terjadi pada dirinya. Para bangsawan tidak akan segan-segan akan menghianati perjuangannya dengan melaporkan dirinya ke 
Belanda karena adanya perasaan pengaruh yang tersaingi oleh Guru Dane.

Pengkhianatan yang dialakukan oleh sahabat Guru Dane sendiri yaitu Ketut Kolang bersama dengan bangsawan Sasak yaitu melaporkan aktivitas yang dilakukan oleh Guru Dane merupakan sebuah pemberontakan sehingga terjadi pertempuran yang mengakibatkan Guru Dane ditangkap. Tertangkapnnya Guru Dane membuat para pengikut Guru Dane menjadi garang dan tidak mau membayar pajak kepada para bangsawan sehinggan Belanda merasa keberatan dan para bangsawan menjadi tertekan.

Cerita terus berkembang ke tahap leraian (D), yakni tertangkapnya Guru Dane membuat keadaan semakin kisruh, bangsawan Sasak semakin miskin, sementara pasukan Belanda semakin tidak tenang akibat para pengikut tidak setia Guru Dane yang masih mendewakannya sehingga para bangsawan Sasak terus mengajukan desakan agar Guru
Dane dihukum. Belanda kemudian menghadirkan saksi-saksi untuk memberatkan keslahaan Guru Dane sampai pada pemanggilan Sumar sebagai saksi kunci. Suamr pun membeberkan seluruh kegiatan yang dilakukan, yakni bahwa selama ini sepengetahuannnya benar. Kesaksian Sumar membuat Belanda menjatuhkan hukuman kepada Guru Dane dengan sah. Cerita pun berjalan ke tahap akhir (E). Pada hari yang sudah ditentukan, pada bulan Januari 1918, Guru Dane diasingkan ke Bali entah ditembak di Buleleng atau di Batavia, ia tak pernah kembali. Semenatra kaum bangsawan Sasak tertawa bergembira di atas penderitaan kaumnya sendiri. Sumar sudah tidak mau peduli terhadap masalah Guru Dane. Ia melanjutkan perjalanan sunyinya untuk melanjutkan perjuangan membangun kesadaran orang Sasak sampai ia meninggal dunia. Alur dalam $N G D$ secara ringkas dapat diperhatikan pada skema alur berikut.
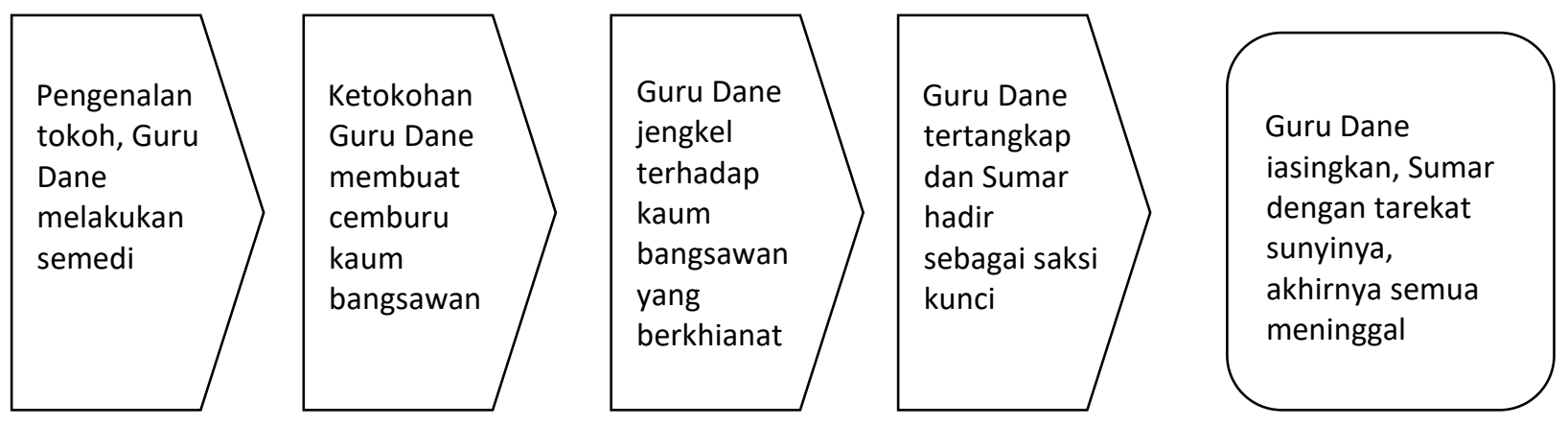

Skema 1. Alur NGD 
Mabasan, Vol. 8, No. 1, januari-Juni 2014: 1-13

4.2 Bentuk-Bentuk Perjuangan Tokoh membangun kesadaran kognitif tentang Utama

Guru Dane merupakan merupakan sosok yang tidak kenal kompromi dan anti kekerasan, menyediakan alternatif bagi orang Sasak. Guru Dane yang lahir dari kalangan buruh tani menjanjikan kebebasan dari ketertindasan, kemiskinan, dan kelaparan bagi orang Sasak. Lelaki yang namanya dipujapuja itu tidak melaksanakan ambisinya untuk mebebaskan orang-orang lemah atas dasar nafsu kekuasaan, tapi ketulusan dan cinta kasih atas nama kekuasaan. Tanpa rasa lelah dan ketegaran yang membaja, ia mengorbankan semangat kebebasan, kesetaraan, dan kemanusiaan. Meskipun pada akhirnya, ia hilang rimba di bawah tekanan penjajah Belanda dan pengkhianatan bangsanya sendiri.

Deskripsi berikut akan dijelaskan bagaimana tokoh Guru Dane dan Sumar melihat Sasak yang sudah lama didera kemiskinan, penderitaan, dan perang saudara. Bentuk-bentuk perjuangan apa saja yang dilakukan sehingga dapat mengangkat harkat dan martabat tanah Lombok ini agar terlepas dari segala kemiskinan dan segala penjajahan.

Bentuk-bentuk perjuangan yang dilakukan oleh Guru Dane, Sumar, dan tokoh lain yang bersimpati dan sepaham dengannya dapat dikelompokkan menjadi lima. Pertama,

kemanusiaan. Kesadaran kognitif merupakan kesadaran pikiran terhadap apa-apa yang sedang berlangsung di sekitar kita. Suatu karya sastra seperti $N G D$ tidak lahir dari ruang hampa melainkan lahir dari kesadaran kognitif pengarang terhadap setting dimana ceritanya berlangsung. Kesadaran itu dimunculkan lewat tokoh yang dibangunnya. Dalam hal ini, keadaan masyarakat Sasak dan Bali di awal abad ke-20 menumbuhkan kesadaran kognitif pada tokoh cerita bahwa orang Sasak dan Bali sampai batas tertentu berada dalam masa kelam.

Kedua, membangun kesadaran sosial. Posisi orang Sasak dikuasai oleh orang Bali dan Belanda. Tiga bangsa atau tiga kesatuan sosial; orang Sasak, orang Bali, dan orang Belanda mendiami kawasan yang sama yaitu Pulau Lombok dengan posisi yang berbeda yaitu dikuasai atau menguasai. Mungkin saja terjadi, orang Sasak awam melihat bahwa orang Bali dan orang Belanda adalah "pemerintah" artinya posisi orang Sasak dikuasai itu wajar saja karena pemerintah menguasai rakyatnya, padahal kalau dilihat secara lebih objektif orang Sasak menjadi budak.

Ketiga, meruntuhkan keangkuhan atau kebesaran yang bergantung kepada bendabenda mistis. Identitas yang sejati adalah 
kualitas kemanusiaan kita, terutama kualitas religiusitas yang dihayati sebagai nilai inti kehidupan. Pengarang melalui tokoh rekaanya meruntuhkan kebanggaan semu yang bersandar pada kesaktian benda yang dianggap keramat seperti keris pusaka. Tokoh Guru Dane meskipun berasal dari rakyat jelata tetapi memiliki kaulitas kemanusiaan yang mulia sehingga dianggap sebagai Raja Selaparang yang menguasai Lombok/Sasak.

Keempat, menanamkan kesadaran kelas. Ideologi kekuasaan dalam $N G D$ didasarkan pada pandangan bahwa dalam masyarakat selalu terjadi pertentangan kelas. Budaya seperti ini, secara ideologis, dicondongkan untuk membenarkan kepeningan kelas. Kekuasan dipegang oleh orang yang memiliki derajat kehidupan dan status sosial lebih tinggi baik dari segi pendidikan, keturunan, maupun kekayaan. Konflik yang dibangun dalam $N G D$ adalah konflik sosial yang luas anatra bangsawan Sasak (sebagai tuan tanah), orang Bali, orang Belanda, dan kebanyakan (awan)yang lapar dan miskin. Kelas proletan dan kelas borjuis yang bekonflik, akhirnya menimbulkan kesaaran kaum proletan untuk bangkit melawan kaum borjuis. Dalam urus konflik itu Guru Dane ada di puasaran arus dan terdepan.

Kelima, menanamkan sifat kesatria sebagai orang Sasak. Kesatria merupakan sifat pemberani. Berani melakukan perlawanan terhadap siapa saja yang melakukan kesalahan baik orang Sasak, Bali, maupun Belanda. Kemudian mampu menanamkan kesadaran kepada orang Sasak tentang penyebab mereka di jajah. Sifat kesatria dapat dilihat dari sikap tokoh Guru Dane yang berani menjadi penggerak pembebasan yang menyerukan kemerdekaan orang Sasak yang tertindas dan mampu menunjukkan bahwa orang Sasak harus kuat untuk bangkit melawan segala penjajahan baik secara fisik maupun akal.

Perbedaan pandangan antara Guru Dane dan anak angkatnya Sumar dalam melihat masalah yang dialami orang Sasak terletak pada bentuk perjuangan yang dilakukan. Perjuangan yang dilakukan Sumar bukan perlawanan fisik seperti yang dilakukan Guru Dane tetapi melakukan penyadaran kepada orang Sasak atas kekalaman yang pernah mereka alami. Sumar memperjuangkan kaum sasak dengan tipe intelektual pemikir karen ia merupakan sosok perempuan yang sangat cepat belajar dan sangat berpotensi menjadi perempuan terpandang dan menjadi pemimpin.

Perjuangan yang dilakukan oleh Guru Dane dan Sumar walaupun berbeda, tetapi pada dasarnya sama yakni bertujuan untuk mengangkat harkat tanah Lombok agar terlepas dari segala kemiskinan dan segala 
penjajahan. Perbedaan perjuangan yang dalam skema berikut. dilakukan oleh Guru Dane dan Sumar terlihat

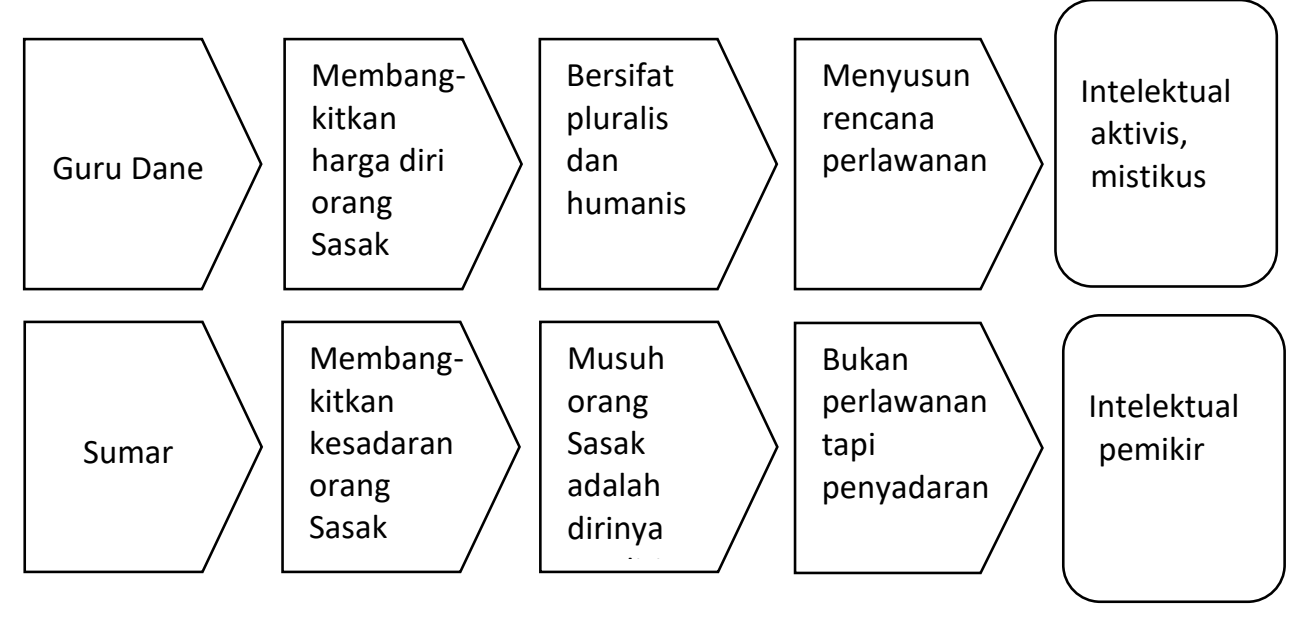

Skema 2. Pebedaan Perjuangan Guru Dane dan Sumar

4.3 Nilai-Nilai Didik dan Relevansinya berkorban dan tanggung jawab, (b) saling dalam Pembelajaran Sastra menghargai hak dan kewajiban, (c) teguh

$N G D$ merupakan salah satu novel yang pendirian dan tahan uji, (d) religious, (e) sabar merefresentasikan kekayaan nilai-nilai dan penyayang, (f) jujur, (g) kerja keras,(h) kehidupan yang positif melalui pendeskripsian kerjasama, dan (i) disiplin. Nilai-nilai tersebut kehidupan tokoh dalam berinteraksi dengan selanjutnya akan dilihat relevansinya dengan masyarakat disekitarnya serta persoalan yang realitas di masyarakat maupun di sekolah yang menimbulkan konflik, baik dari diri tokoh diperoleh dari hasil wawancara dengan maupun dengan orang lain atau masyarakat. responden. Berdasarkan hal itu, akan Dalam interaksi itu terdapat berbagai hal yang ditegaskan keterkaitan antara nilai-nilai berkaitan dengan tutur kata, sikap, perilaku tersebut dengan pembelajaran sastra. Nilai-nilai yang menunjukkan hal-hal positif maupun hal- positif diharapkan dapat diteladani dan hal negatif. Tutur kata, sikap dan perilaku diaplikasikan dalam kehidupan nyata, dalam cerita mengandung nilai-nilai tertentu sedangkan nilai-nilai negatif diperkenalkan yang memberikan sumbangan bagi perbaikan dampak-dampaknya untuk dihindari. Bertitik sikap dan karakter pembaca. tolak dari hal itu, nilai-nilai dalam $N G D$

Nilai-nilaiyang terdapat dalam $N G D$, baik memiliki kelayakan untuk disampaikan kepada nilai positif maupun nilai negatif, yaitu (a) rela siswa melalui pembelajaran sastra. 
Dengan proses di atas, siswa dilatih kecerdasan otak, sosial, maupun spiritual untuk bersikap kritis sehingga dapat menentukan mampu memberdayakan dirinya dan sikap yang tepat dalam menghadapi kehidupan memanusiakan orang lain. Hal ini relevan berdasarkan nilai-nilai yang dipelajari, dengan teori belajar humanistik.

misalnya, pengetahuna siswa tentang bentukbentuk perjuangan tokoh-tokoh dalam masyarakat dikomparasikan dengan nilai-nilai yang dipelajari dalam $N G D$. Nilai-nilai yang baru itu diharpakan akan menumbuhkan kesadaran baru tentang cara yang semestinya dalam bersikap terhadap perbedaan suku, kemudian dari masing-masing bagian, penulis agama, dan budaya dalam kehidupan mencari sebuah makna yang terkait dengan bermasyarakat.

makna bagian-bagian yang lain. Dengan

Pemerolehan dan penerapan nilai seperti demikian, $N G D$ memiliki struktur yang saling dikemukakan di atas, sesuai dengan konsep kait-mengait. Nilai-nilai didik dalam $N G D$ pembelajaran kontekstual yaitu pengaitan dapat direlevansikan dalam pembelajaran sastra amteri yang di ajarkan dengan penerapannya di SMA/MA dengan mengacu kepada dalam kehidupan nyata. Siswa memahami kesesuaian standar isi, standar kompetensi, dan realitas di sekelilingnya; memahami nilai-nilai kompetensi dasar pembelajaran sastra di baru yang berkaitan dengan relitas tersebut; Madrasah Aliyah.

dan mengambil keputusan untuk menerapkan $N G D$ yang dijadikan objek dalam nilai tersebut dalam kehidupan. Dengan penelitian ini mengungkap berbagai aspek demikian, sesuai denga hakikat belajar secara kehidupan manusia. Untuk keperluan kontstrukvistik, siswa membangun sendiri penelitian ini, hanya dikaji salah satu aspek pengetahuan dan kesadarannya berdasarkan dari berbagai aspek yang ada dengan hal-hal yang di pelajari di sekolah maupun menggunakan teori structural-semiotik. Para masyarakat. Dari sudut pandang edukatif, hal peneliti selanjutnya bisa melihat aspek-aspek tersebut akan lebih bermakna bagi siswa karena yang belum diungkap dalam penelitian ini. Di melibatkan pengalaamn siswa secara langsung antara aspek tersebut adalah persoalan gender dalam pembelajaran sehingga pada akhirnya dan psikologis tokoh. Aspek lain yang masih nanti siswa mempunyai kecerdasan baik bisa diungkap dalam $N G D$ ini adlaah gaya 
kepengarangan Salman Faris yang dapat Taniredja, Turkiran, Efi Miftah Faridli, Sri $\begin{array}{lll}\text { dibedah dengan pisau analisis stilistika. Harmianto. (2013). Model-Model } & \text { Mederif }\end{array}$ Pembalajaran Inovatif dan Efektif. Bandung: Alfabeta.

\section{Daftar Pustaka}

Budiningsih. (2004). Pembelajaran Moral Berpijak pada Karakteristik Siswa dan Budayanya. Jakarta: Rineka Cipta.

Badrin. (2013). Potret Perjuangan Tokoh Utama dan Nilai Didik dalam Novel Guru Dane karya Salaman Faris serta Relevansinya dalam Pembelajaran Sastra di MA. Tesis: Universitas Mataram.

Faris, Salman. (2011). Guru Dane. Lombok: STKIP Hamzanwadi Press.

Jabrohim. (2001). Metodologi Penelitian Sastra. Yogyakarta : Hanindata Graha Widy.

Jhonson, B.Elaine. (2011). CTL (Contextual Teaching And Learning). Bandung: Kaifa.

Kraan, van der Alfons. (2009). Lombok: Penaklukan, Penjajahan, dan keterbelakangan 1870-1940. Mataram: Lengge Printika.

Nurgiantoro, Burha. (2010). Teori Pengkajian Fiksi. Yogyakarta. UGM Press.

Ratna, Kutha, (2007). Sastra dan Cultural Studies Refresentasi Fiksi dan Fakta. Yogyakarta: Pustka Pelajar.

Slavin, R. (1994). Educational Psychology, Theory and Practice $\left(4^{\text {th }} \quad\right.$ ed $)$. Masschusetts: Allyn \& Bacon Publisher.
Trianto. (2011). Mendesain Model Pembelajaran Inovatif dan Efektif. Jakarta: Kencana.

Yamin, Martinis. (2008). Paradigma Pendidikan Konstruktivistik. Jakarta: Gaung Persada Press. 